\title{
The Mindful Self: Exploring Mindfulness in Relation with Self- esteem and Self-efficacy in Indian Population
}

\author{
Srishti Chandna $^{1} \cdot$ Pratiksha Sharma $^{1} \cdot$ Harishankar Moosath $^{1}$
}

Received: 26 February 2021 / Accepted: 30 November 2021 / Published online: 2 February 2022

(C) National Academy of Psychology (NAOP) India 2022

\begin{abstract}
The aim of the current study was to evaluate and compare the relationship of mindfulness with self-efficacy and self-esteem. The study has also investigated the difference in mindfulness levels across five dimensions: observing, describing, acting with awareness, non-judging of inner experiences and non-reactivity to inner experience between males and females and between young adults and middle-aged adults who belong to the Indian population. There was a total of 146 participants $(F=80, M=66), 84$ in the young adult group (20-40 years) and 62 participants in the middle adult group (41-65 years). Pearson correlation showed statistically significant $(p<0.01)$ moderate positive correlation between all the five dimensions of mindfulness and self-esteem; while self-efficacy had significant $(p<0.01)$ moderate positive correlation with all the dimensions of mindfulness except for non-judging of inner experiences. Multiple linear regression (MLR) with self-esteem as outcome variable showed model fitness of $51 \%(p<0.01)$ with acting with awareness, non-reactivity to inner experience, non-judging of inner experiences and describing as predictive variables. With self-efficacy as outcome variable, MLR showed model fitness of $40 \%$ $(p<0.01)$ with non-reactivity to inner experiences, acting
\end{abstract}

Srishti Chandna and Pratiksha Sharma are first co-authors.

Srishti Chandna

srishtichandna09@gmail.com

Pratiksha Sharma

pratiksha.sharma@psy.christuniversity.in

Harishankar Moosath

harishankar@christuniversity.in

1 Department of Psychology, CHRIST (Deemed To Be University), Bangalore, India with awareness, observing and describing as predicting variables. Females were found to be significantly higher in acting with awareness and observing dimensions of mindfulness compared to males. Middle adults were found to be significantly higher only in the non-judging of inner experiences dimension as compared to early adults. Importance of mindfulness in improving self-concept has been established in western world. The present study, by exploring the relationship between mindfulness and selfvariables in Indian population, highlights the probable positive outcomes of mindfulness enhancing techniques on self-esteem and self-efficacy of individuals, and therefore on the quality of life.

Keywords Mindfulness · Self-esteem · Self-efficacy · Gender · Age
Abbreviations
MLR Multiple linear regression
MBSR Mindfulness-Based Stress Reduction
FFMQ Five Facet Mindfulness Questionnaire
DASS Depression Anxiety Stress Scale
NSSI Non-suicidal self-injury
RESS Rosenberg Self-esteem Scale
GSE General Self-efficacy Scale
SPSS Statistical Package for Social Science

\section{Introduction}

Over the years, positive psychology has played a substantial role in the field of mental health. From helping individuals manage day-to-day stressors, positive 
psychological intervention has proven to be of significance for those who are struggling with far more serious mental health disorders (Bolier et al., 2013). Mindfulness has been an integral part of positive psychology since the 1970s, when Dr. Jon Kabat-Zinn introduced the stress reduction program, currently known as 'Mindfulness-Based Stress Reduction' (MBSR). Mindfulness finds its roots in early Buddhist teachings and has been a major reformation for the arena of positive psychology (Anonymous, 2015). Mindfulness is the dire necessity of the twenty-first century as with the growing stress levels and workload, patience is a virtue that emerges due to mindful practices (Baxter, 2019). Studies have indicated that individuals have shown a reduction in depression and anxiety levels due to the regular practice of mindfulness exercises (Powell, 2018). Using the Five Facet Mindfulness Questionnaire (FFMQ) and the Depression Anxiety Stress Scale (DASS), it has been learnt that in stressful professions such as medicine, mindfulness led to significantly lower levels of stress, depression and anxiety among medical students (Harshvardhan et al., 2019). It helps us to introspect and focus on our strengths as well as weaknesses. Mindfulness as an intervention strategy has helped in overcoming grief faced by patients with chronic-pain (Sagula \& Rice, 2004).

Positive psychology and mindfulness have been integrated and the relationship between these disciplines has been explored and established (Ivtzan \& Lomas, 2016). Research has been successful in showing that mindfulness has not only enhanced quality of life of individuals with excoriation disorders (Arab et al., 2016), but has also helped individuals with other speech-language pathologies (Medina \& Mead, 2021). Mindfulness practices and positive psychological interventions are found to enhance each other's effectiveness, leading to individual wellbeing (Ivtzan et al., 2016). Mindfulness as described by Nyanaponika Thera (1972) is "the clear and single-minded awareness of what actually happens to us and in us at the successive moments of perception" (p. 5). It is the ability to be present in the moment instead of wandering in the past and future that brings in a lot of efficiency and has a major impact on the psychological wellbeing of individuals (Keng et al., 2011). Other psychological constructs that play a major role in effective dealing with problems include self-esteem and self-efficacy. Both are concepts of self that develop with one's experience relative to the world around.

Positive psychology considers mindfulness, self-esteem and self-efficacy as significant predictors of well-being (Hartman, 2010; Paradise \& Kernis, 2002; Chylova \& Natovova, 2013). Existing literature has explored the relationship between these psychological constructs and suggested that these are interrelated concepts (Rasmussen \& Pidgeon, 2011; Greason \& Cashwell, 2009). Most of the literature involves studies from the west, as positive psychology is still more of a western concept that has not yet attracted much attention in India. The present study focused on exploring these positive psychology constructs in Indian population. Mindfulness can be viewed as a trait as well as a state, both are similar yet responsible for outcomes surpassing each other (Sala et al., 2019). This study focused on trait mindfulness that contemplates individual differences in the general mindfulness levels across state of affairs and time. Whereas, state mindfulness refers to the experience of mindfulness in the given moment (Sala et al., 2019).

Being a part of collectivistic culture like India might increase the sense of responsibilities, irrespective of gender (Verma \& Triandis, 1999). Hence, the significance of positive psychology concepts like self-esteem and self-efficacy can increase several fold and mindfulness might turn out to be a relevant way of enhancing these constructs in an individual. The literature derived has shown a gap in research on self-esteem and self-efficacy in relation to mindfulness in Indian culture and across different age groups and gender. In an attempt to provide objective data on these variables, the present study aims to assess and compare the level of mindfulness among early and middleaged adults across gender in India. This study also aims at exploring the relationship between mindfulness and selfesteem, and mindfulness and self-efficacy in Indian context. Understanding the dynamics between mindfulness, self-esteem and self-efficacy can enhance positive psychological interventions for people who lack belief in self and therefore struggle everyday not only with the outside environment but also with one's inner sense of self.

\section{Mindfulness}

Mindfulness is a human ability to be present in the moment and be fully aware of the current events without getting distracted (Bayes-Fleming et al., 2018). As presented earlier, mindfulness can be bifurcated into state mindfulness and trait or dispositional mindfulness. Moreover, trait mindfulness has been essential in reduction of vulnerability of depression by buffering against rumination and negative bias and by reduction of automatic emotional responding (Sorbero, 2015). Aspects of dispositional mindfulness such as "Acting with Awareness" and "Non-reactivity to inner experiences" has been correlated with higher positive state of mind and perceived health and have led to reduced depression and anxiety levels (Bränström et al., 2011). Demographic studies of trait mindfulness have also reported that the older population has higher trait mindfulness than the younger population. In terms of gender, women have scored higher than men on observing subscale whereas men scored higher than women on acting with awareness subscale of Five Factor Mindfulness 
Questionnaire (Alispahic \& Hasanbegovic-Anic, 2017). State mindfulness, on the other hand, has led to increase in cognitive reappraisal and promotion of emotion regulation (Garland et al., 2013). An Indian study conducted on adolescents, drew conclusions regarding the relationship between coping competence, mindfulness, and well-being. The result suggested a significant positive relationship between all three variables and the multiple regression analyses indicated that both the variables-coping competence and mindfulness together predicted well-being (Padhy et al., 2020).

Mindfulness has been researched upon extensively. It has made a difference in thought processes of individuals and has led to openness and increase in awareness (Keng et al., 2011). Along with this, everyday mindfulness has also been compared with mindfulness during meditation and it has been observed that people who are mindful during everyday life might not be mindful during meditative practices. There seems to be no link between everyday mindfulness and mindfulness during meditation. Moreover, mindfulness can be associated with personality factors as it has been reported that everyday mindfulness can be positively correlated with agreeableness and conscientiousness, and negatively correlated with neuroticism (Thompson \& Waltz, 2007).

Lastly, mindfulness interventions have also led to positive changes across the globe. It has been helpful in aiding to people with substance abuse by reducing their craving levels and increasing mindfulness magnitude (Chiesa \& Serretti, 2013). Mindfulness-based interventions have also shown favorable results among Indian women belonging to rural population who have experienced prenatal grief. It was concluded that the facets of describing, nonreaction, acting with awareness and observation increased over time. Along with this, the psychological well-being of the women also improved post the 12-month follow up (Roberts \& Montgomery, 2016). Mindfulness practices have been associated with healthy eating behavior and have brought a positive change in people with unhealthy eating behavior, such as emotional eating or binge eating (O'reilly et al., 2014). The scope of mindfulness is also rather large in relation to individuals who have been diagnosed with depression and anxiety disorders (Hofmann \& Gómez, 2017).

\section{Mindfulness and Self-esteem}

Self-esteem, in general terms, is an individual's positive evaluation of self (Rosenberg et al., 1995). Self-esteem has often been correlated with leadership qualities, ability to form relationships, depression, anxiety and many other constructs of mental health. High self-esteem has also been associated with high academic performance as well as ability to cope (Baumeister et al., 2003).

Mindfulness and self-esteem have often been linked in researches, with high levels of mindfulness being correlated with high self-esteem. In a study conducted by Pepping et al. (2013), it was reported that reactivity, awareness, non-judging and labeling was associated with high self-esteem but observing could not predict levels of self-esteem. It was further learnt that high self-esteem was correlated with higher life satisfaction. Individuals who were exposed to meditation, as a mindfulness intervention, also reported high state self-esteem. This indicates that state mindfulness is linked to state self-esteem (Pepping et al., 2013). Other than state mindfulness, dispositional mindfulness or rather trait mindfulness has also been related to self-esteem. Individuals with high dispositional mindfulness have high self-esteem and dispositional mindfulness is negatively correlated with social anxiety (Rasmussen \& Pidgeon, 2011). Mindfulness and well-being often go hand in hand and self-esteem plays a rather important role as a catalyst mediating the relationship between the two. Though self-esteem has partially mediated the relationship between mindfulness and negative affect, it has been able to explain the relationship between mindfulness and positive affect (Bajaj et al., 2016).

Mindfulness-based interventions have also been adopted as a way to augment positive virtues such as self-esteem and reduce negative factors such as social anxiety. Goldin and Gross (2010), reported Mindfulness-Based Stress Reduction has been successful in the reduction of social anxiety and elevation of self-esteem. Such interventions have also explored the infamous brain aspect related to mindfulness and directed that there has been a significant change in areas of brain and the behavior relevant to depression, anxiety and self-esteem (Goldin \& Gross, 2010). Mindfulness-Based Stress Reduction intervention has also led to improvement among prisoners and has shown increased levels of self-esteem, reduction in hostility and elevated mood. Women have reported higher improvement than men (Samuelson et al., 2007).

Mindfulness has proven to be efficient and effective while enhancing self-esteem as supported by the presented literature. Mindfulness also has a strong relationship with self-efficacy and has proven to augment the same.

\section{Mindfulness and Self-efficacy}

According to Bandura, self-efficacy is the belief about one's capabilities and present resources to successfully attain a task or situation. It can be closely related to one's performance as well (McCormick, 2001). Mindfulness and self-efficacy have often been studied in depth and as part of various fields. 
Research has indicated that mindfulness has a significant impact on intensity of self-efficacy across various groups. Moreover, dispositional mindfulness can be linked to aspects such as academic self-efficacy and positive reappraisal. On various occasions positive reappraisal functions as a mediator between mindfulness and academic self-efficacy (Hanley et al., 2015). Self-efficacy and mindfulness have also been associated with non-suicidal self-injury (NNSI) and it has been reported that mindfulness was positively correlated with coping self-efficacy among students. Students who engage in NSSI group have exhibited lower levels of mindfulness, and coping self-esteem, and coping self-efficacy was found to play the role of a mediator between mindfulness and NSSI (Heath et al., 2016). It is difficult to generalize data that is provided in the study solely because the study only focuses on college students just like the previous study related to academic self-efficacy (Hanley et al., 2015). Mindfulness, self-efficacy and gender has been studied in relation to mental health variables like depression, anxiety, well-being and stress, providing evidence for predictive nature of mindfulness along with self-efficacy and gender for mental health (Soysa \& Wilcomb, 2013).

Self-efficacy and mindfulness are further studied in the field of psychology in relation to personal strengths of psychology students as well. There exists a positive relationship between mindfulness and counsellor self-efficacy among psychology students, indicating the importance of mindfulness for counselling efficiency. Attention has been reported to carry the mediator function between mindfulness and counselor self-efficacy (Greason \& Cashwell, 2009). Other than psychology students, nursing students have revealed a decline in depression, perceived stress and an increase in self-efficacy, after being exposed to 8-week long mindfulness-based intervention (Yeom \& Choi, 2013). Self-efficacy and mindfulness are still being studied extensively but there has been a lack of data of the same in the Indian context.

Although existing literature has highlighted the empirical findings on significance of mindfulness and its relationship with psychological variables (Goldin \& Gross, 2010; Heath et al., 2016; Rasmussen \& Pidgeon, 2011; Soysa \& Wilcomb, 2013; Yeom \& Choi, 2013), most of the studies have been conducted in the west. Indian literature on mindfulness has barely focused on its relationship with other psychological variables across age and gender. Moreover, understanding the interplay of these variables could be useful in therapeutic settings owing to the role of self-concept in alleviating mental health problems as well as maintaining psychosocial wellness. Therefore, this study intends to explore mindfulness in relation to self-esteem and self-efficacy in early and middle-aged adults in India.

\section{Hypotheses}

The study hypothesizes that there will be a positive correlation between mindfulness and self-esteem; and between mindfulness and self-efficacy. Self-esteem and self-efficacy can be significantly predicted by mindfulness to a certain extent in Indian population. Moreover, the level of mindfulness will be higher in middle adults compared to early adults and; the level of mindfulness will be higher in females compared to males.

\section{Methodology}

\section{Research Design}

A quantitative research design was used to explore the objectives of the study. To maintain the congruence with the objectives of the study, correlation design was used in order to assess the association between mindfulness, selfesteem and self-efficacy. Between-group design was adopted to compare the variables- mindfulness, self-efficacy and self-esteem, between males and females, and between early aged adults and middle-aged adults.

\section{Participants}

The sample included males and females belonging to the early aged adult group (20-40 years) and middle-aged adult group (41-65 years). Overall, 262 individuals were recruited for the study by employing convenient sampling method, but 146 participants $(F=80, M=66)$ were selected for the final data analysis and were grouped into early adults $(N=84)$ between the ages of 20-40 years and middle adults $(N=62)$ between the ages of 41-65 years. The sample was collected from different states of India through the means of google forms and by the help of friends, teachers and family. Participants who reported that they were diagnosed with a mental health disorder and those who engaged in mindfulness-based practices, at least once in a week, were excluded from the study.

\section{Tools}

\section{Five Facet Mindfulness Questionnaire}

Was developed by Ruth A. Baer of University of Kentucky in 2006. It is a self-report measure of mindfulness that consists of 39 items covering five factors viz. observing, describing, acting without awareness, non-judging of inner experiences and non-reactivity to inner experience. It is a five-point Likert scale to which a participant responds based on his opinion that is true for the given statements, 
ranging from 1 to 5 , where $1=$ Never or very rarely true, and $5=$ Very often or always true. The scale has items that have to be scored in reverse manner. Confirmatory factor analysis has shown that all the four factors except observing have expected relationships with other variables related to mindfulness. Factor observing shows expected as well as unexpected relationship with these variables $($ Baer et al., 2006).

\section{Rosenberg Self-esteem Scale (RSES)}

The instrument was developed by Morris Rosenberg in 1960. It is a self-report, unidimensional measure of selfesteem consisting of 10 items. Items are answered on a 4-point Likert scale ranging from strongly agree to strongly disagree. The tool measures both positive and negative feelings about self where the items related to the latter have reverse scoring. Internal consistency of the scale was found to be 0.77 (Rosenberg, 1965).

\section{General Self-efficacy Scale (GSE)}

The instrument was developed by Matthias Jerusalem and Ralf Schwarzer in 1981. It is a self-report measure of selfefficacy consisting of 10 items. Items are answered on a 4-point likert scale ranging from not at all true to exactly true. The total scores can range from 10 to 40 , with higher scores indicating more self-efficacy. Internal reliability in the form of Cronbach's alpha is between 0.76 and 0.90 for GSE. Validity of the scale was established by its positive correlation with optimism, work satisfaction and its negative correlation with depression, stress, anxiety etc. (Schwarzer \& Jerusalem, 1995).

\section{Procedure}

Data collection was done online using google forms. The survey form was created with different sections devoted to the following: (1) Description of the study, and researchers, (2) Informed Consent, (3) Demographic data sheet having questions to divide participants into different groups and ensure inclusion and exclusion criteria, (4) Three different sections for mindfulness, self-esteem and self-efficacy questionnaires. The researchers used social media to expand their reach in order to get diverse data. Total of 262 individuals filled the survey. Data was then cleaned and participants who practiced mindfulness through the means of yoga or deep breathing exercises were dropped out along with those who reported being diagnosed with any mental health disorder. Only 146 participants $($ Males $=66$, Female $=80$ ) were selected for the final data analysis. Participants falling in the age group of $20-40$ years were categorized as early adults and those falling in the age group of 41-65 years were categorized as middle adults.

\section{Statistical Analysis}

Data was analyzed using Statistical Package for Social Science (SPSS v.25). The reliability coefficient was computed for five subscales of mindfulness questionnaire, selfesteem and self-efficacy scales. The data were analyzed for normal distribution using Shapiro-Wilk. Self-esteem and Acting with awareness dimension of Mindfulness were found to be normally distributed. Self-efficacy, and mindfulness dimensions-observing, describing, non-judging of inner experiences and non-reactivity to inner experiences were normalized in SPSS. $T$-test was conducted to compare the participants across age and gender on the variable of mindfulness and Pearson Product Moment Correlation was conducted to assess the relationship between 5 dimensions of mindfulness and self-esteem, and self-efficacy. Finally, multiple linear regression was conducted to assess the predictive ability of mindfulness (measured by 5 dimensions) for self-esteem and self-efficacy.

\section{Results}

Based on inclusion and exclusion criteria, data was analyzed for 146 participants out of 282 individuals who filled the survey form. Mean age for participants was 34.5 years (minimum $=12 ;$ maximum $=60)$. In the age category, $57.5 \%(N=84)$ participants were early adults and $42.5 \%$ $(N=62)$ were middle adults. In the gender category, $54.8 \%(N=80)$ participants were female and $45.2 \%$ $(N=66)$ were males. To maintain homogeneity across all the scales of mindfulness, self-esteem and self-efficacy, instead of sum, mean scores on the scales have been used to run all the statistical analysis.

Table 1 represents correlation matrix and descriptive statistics for the study variables. Among dimensions of mindfulness, describing and acting with awareness had the highest mean in the sample, while the mean of self-efficacy was higher than self-esteem. Results indicated that selfesteem is positively correlated with all the dimensions of mindfulness (observing, $r=0.313, p<0.01$; describing, $r=0.497, p<0.01$; acting with awareness, $r=0.553$, $p<0.01$; non-judging of inner experiences, $r=0.433$, $p<0.01$; non-reactivity to inner experiences, $r=0.497$, $p<0.01$ ). Also, self-efficacy appears to have significantly positive correlation with all the dimensions of mindfulness (observing, $r=0.382, p<0.01$; describing, $r=0.478$; acting with awareness, $r=0.553, p<0.01$; non-reactivity to inner experiences, $r=0.562, p<0.01)$ except nonjudging of inner experiences $(r=0.152, p>0.05)$. As 
Table 1 Descriptive and correlation statistics of study variables

\begin{tabular}{|c|c|c|c|c|c|c|c|}
\hline Variables & $\begin{array}{l}\text { Self- } \\
\text { esteem }\end{array}$ & $\begin{array}{l}\text { Self- } \\
\text { efficacy }\end{array}$ & Observing & Describing & $\begin{array}{l}\text { Acting with } \\
\text { awareness }\end{array}$ & $\begin{array}{l}\text { Non-judging of inner } \\
\text { experiences }\end{array}$ & $\begin{array}{l}\text { Nonreactivity to inner } \\
\text { experiences }\end{array}$ \\
\hline Self-esteem & 1 & & & & & & \\
\hline Self-efficacy & $0.659 * *$ & 1 & & & & & \\
\hline Observing & $0.313 * *$ & $0.382^{*}$ & 1 & & & & \\
\hline Describing & $0.497 * *$ & $0.478^{* *}$ & $0.331 * *$ & 1 & & & \\
\hline Acting with awareness & $0.553 * *$ & $0.441 * *$ & $241 * *$ & $0.399 * *$ & 1 & & \\
\hline $\begin{array}{l}\text { Non-judging of inner } \\
\text { experiences }\end{array}$ & $0.433 * *$ & 0.152 & 0.070 & 0.113 & $0.292 * *$ & 1 & \\
\hline $\begin{array}{l}\text { Nonreactivity to inner } \\
\text { experience }\end{array}$ & $0.497 * *$ & $0.526 * *$ & $0.417 *$ & $0.571 * *$ & $0.320 * *$ & 0.145 & 1 \\
\hline Mean & 2.77 & 2.88 & 3.22 & 3.32 & 3.25 & 2.92 & 3.10 \\
\hline S.D & 0.64 & 0.63 & 0.76 & 0.78 & 0.86 & 0.63 & 0.61 \\
\hline
\end{tabular}

$N=146$

$* p<0.05 ; * * p<0.01$

illustrated, self-esteem and self-efficacy showed moderate link with observing, describing, acting with awareness, non-judging of inner experiences (low with self-efficacy) and non-reactivity to inner experiences.

In order to identify whether or not five dimensions of mindfulness can predict self-esteem and self-efficacy, stepwise multiple linear regression analyses were conducted for both variables separately.

Table 2 shows the final model of stepwise multiple linear regression performed separately with self-esteem (a) and self-efficacy (b) as dependent variables. The results indicated that Acting with awareness $(t=4.58, p<0.01)$, Non-judging to inner experiences $(t=4.32, p<0.01)$, Non-judging of inner experiences $(t=3.52, p<0.01)$ and Describing $(t=3.50, p<0.05)$ significantly predicted self- esteem. $R^{2}$ indicates that $51 \%(p<0.01)$ of the total variance in the self-esteem can be explained by these domains of mindfulness. The beta value shows that acting with awareness $(\beta=0.31)$ is the strongest predictor of selfesteem followed by Non-reactivity to inner experiences ( $\beta=0.26)$, Non-judging of inner experiences $(\beta=0.27)$ and Describing $(\beta=0.19)$. Observing dimension was unable to predict self-esteem.

Regarding self-efficacy, the results indicated that nonreactivity to inner experiences $(t=3.40, p<0.01)$, Acting with awareness $(t=2.88, p<0.01)$, Observing $(t=2.37$, $p<0.05)$ and Describing $(t=2.04, p<0.05)$ significantly predict self-efficacy. $R^{2}$ indicates that $40 \%(p<0.01)$ of the total variance in the self-esteem can be explained by these domains of mindfulness. The beta value indicates that

Table 2 Regression analysis of Self-esteem and self-efficacy with 4 domains of mindfulness

\begin{tabular}{|c|c|c|c|c|c|c|}
\hline Predictor variable & Beta value & $T$ & $R^{2}$ & Adjusted $R^{2}$ & $F$ & Sig \\
\hline \multicolumn{7}{|l|}{ (a) Dependent variable: self-esteem } \\
\hline Acting with awareness & 0.31 & $4.58 * *$ & & & & \\
\hline Non-judging of inner experiences & 0.27 & $4.32 * *$ & 0.51 & 0.50 & $35.32 * *$ & $<0.01$ \\
\hline Non-reactivity to inner experiences & 0.26 & $3.52 * *$ & & & & \\
\hline Describing & 0.19 & $3.50 *$ & & & & \\
\hline \multicolumn{7}{|l|}{ (b) Dependent variable: self-efficacy } \\
\hline Non-reactivity of inner experiences & 0.29 & $3.40 * *$ & & & & \\
\hline Acting with awareness & 0.21 & $2.88 * *$ & 0.40 & 0.38 & $22.15^{* *}$ & $<0.01$ \\
\hline Observing & 0.18 & $2.37 *$ & & & & \\
\hline Describing & 0.17 & $2.04 *$ & & & & \\
\hline
\end{tabular}

$* p<0.05 ; * * p<0.01$

Excluded variable (a): Observing.

Excluded variable (b): Non-judging of inner experiences. 
Non-reactivity to inner experiences $(\beta=0.29)$ is the strongest predictor of self-esteem followed by Acting with awareness $(\beta=0.21)$, Observing $(\beta=0.18)$ and Describing $(\beta=0.17)$. Non-judging of inner experiences dimension of mindfulness fails to predict self-efficacy.

Table 3 represents descriptive and $t$-statistics for five dimensions of mindfulness among young and middle adults. The results indicate that young adults $(M=2.81$, $\mathrm{SD}=0.67)$ and middle-aged adults $(M=3.04, \mathrm{SD}=0.55)$ differ significantly on Non-Judging of inner experiences dimension $(t=-2.17, p<0.05)$ of mindfulness. However, results showed that young and middle-aged adults do not differ significantly on observing, describing, acting with awareness and non-reactivity to inner experiences dimensions of mindfulness.

Table 4 represents descriptive and $t$-statistics for five dimensions of mindfulness among males and females. The results indicate that males $(M=3.08, \mathrm{SD}=0.85)$ and females $(M=3.40, \mathrm{SD}=0.84)$ differ significantly on Acting with awareness dimension $(t=2.23, p<0.05)$ of mindfulness. Also, males $(M=3.01, \mathrm{SD}=0.85)$ are significantly different from females $(M=3.39, \mathrm{SD}=0.62)$ on observing dimension $(t=3.28, p<0.1)$ of mindfulness. However, males and females do not display significant differences in describing, non-judging of inner experiences and non-reactivity to inner experiences.

\section{Discussion}

The purpose of this study was twofold. First, the study was designed to examine how mindfulness could be related to self-esteem and self-efficacy, and whether mindfulness can predict these two concepts of self-psychology. Second, the study aimed at inspecting whether there exists a difference in the level of mindfulness across gender (males and females) and age (early adults and middle adults). The study intended at exploring these variables in the Indian adult population.

Table 3 Independent Sample t-test showing the difference on five domains of mindfulness between young adults and middle adults

\begin{tabular}{|c|c|c|c|c|}
\hline Variable & Groups & Mean & SD & $\mathrm{T}$ \\
\hline \multirow[t]{2}{*}{ Observing } & Young adults & 3.28 & 0.64 & \multirow[t]{2}{*}{1.21} \\
\hline & Middle adults & 3.12 & 0.64 & \\
\hline \multirow[t]{2}{*}{ Describing } & Young adults & 3.30 & 0.83 & \multirow[t]{2}{*}{-0.34} \\
\hline & Middle adults & 3.34 & 0.70 & \\
\hline \multirow[t]{2}{*}{ Acting with awareness } & Young adults & 3.19 & 0.88 & \multirow[t]{2}{*}{-1.04} \\
\hline & Middle adults & 3.34 & 0.83 & \\
\hline \multirow[t]{2}{*}{ Non-Judging of inner experiences } & Young adults & 2.81 & 0.67 & \multirow[t]{2}{*}{$-2.17 *$} \\
\hline & Middle adults & 3.04 & 0.55 & \\
\hline \multirow[t]{2}{*}{ Nonreactivity to inner experiences } & Young adults & 3.11 & 0.59 & \multirow[t]{2}{*}{0.19} \\
\hline & Middle adults & 3.09 & 0.63 & \\
\hline
\end{tabular}

$* p<0.05$.

Table 4 Independent sample $t$-test showing the difference on five domains of mindfulness between males and females

\begin{tabular}{lllll}
\hline Variable & Groups & Mean & SD & \\
\hline Observing & Female & 3.39 & 0.62 & 0.85 \\
& Male & 3.01 & 0.76 & $0.89^{* *}$ \\
Describing & Female & 3.40 & 0.47 \\
& Male & 3.21 & 0.85 & $2.23^{*}$ \\
Acting with awareness & Female & 3.40 & 0.65 & 0.19 \\
Non-judging of inner experiences & Male & 3.08 & 0.61 & 0.53 \\
Nonreactivity to inner experiences & Female & Male & 2.92 & 0.70 \\
\end{tabular}

$* p<0.05 ; * * p<0.01$ 
The Relationship between Mindfulness and Selfesteem and Self-efficacy

Firstly, we explored the relationship of mindfulness with self-esteem and self-efficacy, and as predicted, results showed that self-esteem and self-efficacy were positively correlated with mindfulness. All the five dimensions of mindfulness viz. observing, describing, acting with awareness, non-judging of inner experiences and non-reactivity to inner experiences were found to be significantly correlated with self-esteem in moderate range. The results are in line with previous research presenting positive correlation between trait mindfulness and self-esteem (Randal et al., 2015; Chalk, 2016; Park \& Dhandra, 2017; Bajaj et al., 2019). In the present study, self-efficacy was found to have moderate and significant positive correlation with observing, describing, acting with awareness, and non-reactivity to inner experiences. However, self-efficacy has an insignificant, weak positive correlation with non-judging of inner experiences dimension of mindfulness. In line with previous studies that have shown a positive relationship between mindfulness and academic self-efficacy (Hanley et al., 2015), professional self-efficacy (Greason \& Cashwell, 2009; Pineau et al., 2014; Rayan, 2018), coping selfefficacy (Fallah, 2017; Heath et al., 2016), counselling selfefficacy (Wei et al., 2015), our study has demonstrated this relationship of mindfulness with general self-efficacy of adults.

Subsequently, we investigated the predictive ability of mindfulness for variables, self-esteem and self-efficacy. As anticipated, study results provided evidence that self-esteem and self-efficacy can be predicted by mindfulness. Results of regression analysis for self-esteem showed that higher levels of acting with awareness, non-reactivity to inner experiences, non-judging of inner experiences and describing positively predicted self-esteem in Indian population, however, the observing dimension failed to predict self-esteem. Overall, the model fitness was found to be $50 \%$ with acting with awareness being the strongest and describing being the weakest predictor of self-esteem. These results are compatible with previous studies demonstrating dimensions of FFMQ as predictor of selfesteem (Heppner \& Kernist, 2011; Hinterman et al., 2012; Pepping et al., 2013;). Studies involving mediation analysis has provided evidence for predictive interaction between mindfulness and self-esteem in context of mental health variables like stress, quality of life (Vosvick \& Stem, 2019), depression (Hinterman et al., 2012), happiness (Bajaj et al., 2019), social media use (Apaolaza et al., 2019; Yang et al., 2017) and consumer psychology variables like impulsive buying (Dhandra, 2020). Mindful awareness and processing of self-depleting thoughts of worthlessness reduces the negative impact of such cognition on human behavior (Marshall et al., 2015). This finding is suggestive of potential effectiveness of mindfulness-based intervention in improving self-esteem in the adult population similar to that found in adults with social anxiety disorder to reduce negative self-belief (Goldin \& Gross, 2010) and in undergraduate students to enhance self-esteem (Pepping et al., 2013).

The regression model for self-efficacy showed that higher levels of non-reactivity to inner experiences, acting with awareness, observing, and describing, positively predicted self-efficacy in Indian population, however, nonjudging of inner experiences did not predict self-esteem. Non-reactivity to inner-experiences was found to be the strongest predictor of self-efficacy and the overall model fitness is low (40\%). These findings are consistent with existing studies that relate higher mindfulness with higher academic self-efficacy among students (Hanley et al., 2015), and with higher counselling self-efficacy among trainee counsellors (Butts \& Gutierrez, 2018; Greason \& Cashwell, 2009), coping self-efficacy (Fallah, 2017) and general self-efficacy (Chang et al., 2004; Caldwell et al., 2010; Charoensukmongkol, 2014). It suggests that, strengthening trait mindfulness can help enhance self-efficacy among adults. Mindfulness-based interventions have the potential to enhance mindfulness which in turn can enhance individual's level of professional and general selfefficacy (Chang et al., 2004; Young-Ran \& Keum-Bong, 2013; Katan et al., 2019; Yeom \& Choi, 2013; Charoensukmongkol, 2014; Vidic \& Cherup, 2019). Although the majority of studies supported the idea, Firth et al. (2019) presented contradictory evidence of decrement in self-efficacy following mindfulness intervention.

\section{Mindfulness across Age and Gender}

Next, we analyzed the heterogeneity of trait mindfulness between young and middle-aged adults as well as between males and females. Interestingly, and opposed to our expectations, results showed that young and middle-aged adults differ significantly only on the Non-Judging of inner experiences dimension of mindfulness, indicating that middle adults have higher self-acceptance and unconditional empathy for oneself and others. Although, middleaged adults were also found to be higher on Describing and Acting with awareness dimensions but the differences are insignificant. Hence, the hypothesis of the study about middle-aged adults being more mindful than young adults stands questionable as the latter, though insignificant, were found to be higher on other two domains of mindfulnessobserving and non-reactivity to inner experiences. These findings contradict the results from previous studies that on the one hand supports that all the dimensions of mindfulness increase with age (Splevins et al., 2009; Aliphatic \& 
Hasanbegovic-Anic, 2017), while other studies on mindfulness have concluded that trait mindfulness does not vary with age (Leavitt et al., 2019). Irregularities across studies in the level of mindfulness pertaining to age makes it difficult to conclusively state age as a factor associated with mindfulness and hence require further extensive research.

Results of mindfulness across gender shows that females compared to males are higher in the observing dimension of mindfulness which is in line with existing studies on mindfulness (Aliphatic \& Hasanbegovic-Anic, 2017). However, this study provides evidence that females as compared to males are higher in the Acting with awareness dimension of mindfulness which is contradictory to other studies assessing mindfulness across gender (Aliphatic \& Hasanbegovic-Anic, 2017; Leavitt et al., 2019). The present investigation hypothesized that females are more mindful than males which was supported by the derived results. However, an exception of non-judging of inner experiences was present, where both males and females have equal mean scores. Apart from this, females show higher mean scores compared to males on all the dimensions of mindfulness. There are very few studies exploring gender differences in mindfulness and the ones that did explore this relationship has provided inconsistent results (Leavitt et al., 2019; Aliphatic \& HasanbegovicAnic, 2017; Soysa \& Wilcomb, 2013). The inconsistency can be speculated to be related to cultural differences, indicating a need for cross cultural study to explore in depth the gender related differences in mindfulness.

\section{Conclusion}

Positive psychology is a relatively upcoming field and mindfulness, as an important aspect associated with the field, has been studied and researched in relation to various psychological constructs. Despite being extensively researched upon, mindfulness lacks data in connection with individual factors, such as age and gender, therefore, there is a requirement and scope for more detailed research in this arena. In this study, gender differences were evident with females being more observant of the internal and external world and higher in calculated actions instead of responding in autopilot mode. The differences highlighted between men and women on the five facets of mindfulness could be beneficial in developing the gender specific mindfulness-based interventions. Positive correlation of various dimensions of mindfulness with self-esteem and self-efficacy indicates usefulness of self-awareness (internal and external) in improving self-concepts. Though with insufficient model fitness, dimensions of mindfulness (measured as a trait) were able to predict self-esteem and self-efficacy. Mindfulness has taken front seat in the field of mental health along with other therapeutic models like cognitive-behavioral therapy and person-centered therapy. Developing state mindfulness might be difficult in a short time period, and people tend to give up easily. But exploring and strengthening the trait mindfulness in oneself could be of substantial use considering that a lot of mental health issues in today's rapidly evolving world concerns poorly developed self-concept.

One of the shortcomings of the study is small sample size $(N=146)$. Results based on such small samples become strenuous to generalize and, therefore, similar research with a large sample size is recommended to see a more accurate interplay of mindfulness with self-esteem and self-efficacy. Moreover, the data was collected in the middle of a pandemic (Covid 19) which can be considered as a major limitation as it might influence the responses of the participants. There is a dire need for extensive research in the area of mindfulness in relation to gender and age groups in order to develop interventions that are suitable on the basis of individual requirements. Future researchers could focus on conducting study to evaluate if mindfulness relates differently to self-esteem and self-efficacy across gender and age groups. Since the scope of positive psychology is wide and mindfulness stems from the roots of this field, especially in a country like India which believes in alternative methods of therapy such as yoga and exercise, such studies can be of high value.

Acknowledgements We express our deepest gratitude to CHRIST (deemed to be) University for giving us the time and space to explore this topic. Along with this we would like to thank Dr. Santhosh K. R. and Dr. Jacqueline Kareem for their constant support and guidance. We would also like to thank TSVS Bhargav for his encouragement and insight.

Author's Contribution Conception or design of the work: Srishti Chandna and Pratiksha Sharma. Data collection: Srishti Chandna (Major) and Pratiksha Sharma. Data analysis and Interpretation: Pratiksha Sharma (Major) and Srishti Chandna. Drafting the article: Pratiksha Sharma and Srishti Chandna. Critical revision of the article: Harishankar Moosath. Final approval of the version to be published: Harishankar Moosath, Srishti Chandna, Pratiksha Sharma.

Funding No funding.

Availability of Data and Materials Data that supports the findings of the study are available from the corresponding authors upon reasonable request.

\section{Declarations}

Conflict of interest The authors declare that they have no conflict of interest.

Ethics Approval The study proposal has been exempted from review by Research Conduct and Ethics Committee of CHRIST (Deemed to be) University under IRB No. CU: RCEC/00249/11/21. 
Consent to Participate Participants signed an informed consent (online) before participating in the study. They were informed about the purpose of the study, terms of confidentiality and right to withdrawal.

Consent for Publication We the undersigned, give our consent for the publication of identifiable details, which can include photograph(s) and/or videos and/or case history and/or details within the text ("Material") to be published in the above Journal.

\section{References}

Alispahic, S., \& Hasanbegovic-Anic, E. (2017). Mindfulness: Age and gender differences on a Bosnian sample. Psychological Thought, 10(1), 155-166. https://doi.org/10.5964/psyct.v10i1. 224

Apaolaza, V., Hartmann, P., D’Souza, C., \& Gilsanz, A. (2019). Mindfulness, compulsive mobile social media use, and derived stress: The mediating roles of self-esteem and social anxiety. Cyberpsychology, Behavior, and Social Networking, 22(6), 388-396.

Arab, M. H., Baghouli, H., \& Barzegar, M. (2016). Effectiveness of mindfulness-based therapy on symptoms reduction and improving quality of life in patients with excoriation disorder. Indian Journal of Positive Psychology, 7(4), 414-417.

Baer, R. A., Smith, G. T., Hopkins, J., Krietemeyer, J., \& Toney, L. (2006). Using self-report assessment methods to explore facets of mindfulness. Assessment, 13(1), 27-45. https://doi.org/ $10.1177 / 1073191105283504$

Bajaj, B., Gupta, R., \& Pande, N. (2016). Self-esteem mediates the relationship between mindfulness and well-being. Personality and Individual Differences, 94, 96-100. https://doi.org/10.1016/ j.paid.2016.01.020

Bajaj, B., Gupta, R., \& Sengupta, S. (2019). Emotional stability and self-esteem as mediators between mindfulness and happiness. Journal of Happiness Studies, 20(7), 2211-2226.

Baumeister, R. F., Campbell, J. D., Krueger, J. I., \& Vohs, K. D. (2003). Does high self-esteem cause better performance, interpersonal success, happiness, or healthier lifestyles? Psychological Science in the Public Interest, 4(1), 1-44. https://doi.org/ 10.1111/1529-1006.01431

Baxter, C. (2019). The Benefits of Meditation and Mindfulness in the 21st Century. ZANI. https://zani.co.uk/zani-culture/item/2879the-benefits-of-meditation-and-mindfulness-in-the-21st-century.

Bayes-Fleming, N., PhD, B. G. B., Boyce, B., Goh, C., Newman, K. M., Staff, M., \& Graham, L. (2018). Getting Started with Mindfulness. Mindful. https://www.mindful.org/meditation/ mindfulness-getting-started/.

Bolier, L., Haverman, M., Westerhof, G. J., Riper, H., Smit, F., \& Bohlmeijer, E. (2013). Positive psychology interventions: a meta-analysis of randomized controlled studies. BMC Public Health. https://doi.org/10.1186/1471-2458-13-119

Bränström, R., Duncan, L. G., \& Moskowitz, J. T. (2011). The association between dispositional mindfulness, psychological well-being, and perceived health in a Swedish population-based sample. British Journal of Health Psychology, 16(2), 300-316. https://doi.org/10.1348/135910710x501683

Butts, C. M., \& Gutierrez, D. (2018). Dispositional mindfulness and personal distress as predictors of counseling self-efficacy. Counselor Education and Supervision, 57(4), 271-284.

Caldwell, K., Harrison, M., Adams, M., Quin, R. H., \& Greeson, J. (2010). Developing mindfulness in college students through movement-based courses: Effects on self-regulatory self- efficacy, mood, stress, and sleep quality. Journal of American College Health, 58(5), 433-442.

Chalk, H. M. (2016). Disability self-categorization in emerging adults: Relationship with self-esteem, perceived esteem, mindfulness, and markers of adulthood. Emerging Adulthood, 4(3), 200-206.

Chang, V. Y., Palesh, O., Caldwell, R., Glasgow, N., Abramson, M., Luskin, F., Gill, M., Burke, A., \& Koopman, C. (2004). The effects of a mindfulness-based stress reduction program on stress, mindfulness self-efficacy, and positive states of mind. Stress and Health, 20(3), 141-147. https://doi.org/10.1002/ smi.1011

Charoensukmongkol, P. (2014). Benefits of mindfulness meditation on emotional intelligence, general self-efficacy, and perceived stress: Evidence from Thailand. Journal of Spirituality in Mental Health, 16(3), 171-192.

Chiesa, A., \& Serretti, A. (2013). Are mindfulness-based interventions effective for substance use disorders? A systematic review of the evidence. Substance Use and Misuse, 49(5), 492-512. https://doi.org/10.3109/10826084.2013.770027

Chylová, H., \& Natovová, L. (2013). 'Stress, self-efficacy and wellbeing of the university students. Journal on Efficiency and Responsibility in Education and Science, 6(3), 190-202. https://doi.org/10.7160/eriesj.2013.060306

Dhandra, T. K. (2020). Does self-esteem matter? A framework depicting role of self-esteem between dispositional mindfulness and impulsive buying. Journal of Retailing and Consumer Services, 55, 102135.

Fallah, N. (2017). Mindfulness, coping self-efficacy and foreign language anxiety: A mediation analysis. Educational Psychology, 37(6), 745-756.

Firth, A. M., Cavallini, I., Sütterlin, S., \& Lugo, R. G. (2019). Mindfulness and self-efficacy in pain perception, stress and academic performance. The influence of mindfulness on cognitive processes. Psychology Research and Behavior Management, 12,565 .

Garland, E. L., Hanley, A., Farb, N. A., \& Froeliger, B. (2013). State mindfulness during meditation predicts enhanced cognitive reappraisal. Mindfulness, 6(2), 234-242. https://doi.org/10.1007/ s12671-013-0250-6

Goldin, P. R., \& Gross, J. J. (2010). Effects of mindfulness-based stress reduction (MBSR) on emotion regulation in social anxiety disorder. Emotion, 10(1), 83-91. https://doi.org/10.1037/a001 8441

Greason, P. B., \& Cashwell, C. S. (2009). Mindfulness and counseling self-efficacy: The mediating role of attention and empathy. Counselor Education and Supervision, 49(1), 2-19. https:// doi.org/10.1002/j.1556-6978.2009.tb00083.x

Hanley, A. W., Palejwala, M. H., Hanley, R. T., Canto, A. I., \& Garland, E. L. (2015). A failure in mind: Dispositional mindfulness and positive reappraisal as predictors of academic self-efficacy following failure. Personality and Individual Differences, 86, 332-337. https://doi.org/10.1016/j.paid. 2015.06.033

Hartman, T. R. (2010). Mindfulness and well-being: Testing for mediation and predictiveness. Masters Theses. 606. http:// thekeep.eiu.edu/theses/606.

Heath, N. L., Joly, M., \& Carsley, D. (2016). Coping self-efficacy and mindfulness in non-suicidal self-injury. Mindfulness, 7(5), 1132-1141. https://doi.org/10.1007/s12671-016-0555-3

Heppner, W. L., \& Kernis, M. H. (2011). High self-esteem: Multiple forms and their outcomes. In Handbook of identity theory and research (pp. 329-355). Springer.

Hinterman, C., Burns, L., Hopwood, D., \& Rogers, W. (2012). Mindfulness: Seeking a more perfect approach to coping with life's challenges. Mindfulness, 3(4), 275-281. 
Hofmann, S. G., \& Gómez, A. F. (2017). Mindfulness-based interventions for anxiety and depression. Psychiatric Clinics of North America, 40(4), 739-749. https://doi.org/10.1016/j.psc. 2017.08.008

Ivtzan, I., \& Lomas, T. (2016). Mindfulness in positive psychology: The science of meditation and wellbeing. Routledge.

Ivtzan, I., Young, T., Martman, J., Jeffrey, A., Lomas, T., Hart, R., \& Eiroa-Orosa, F. (2016). Integrating mindfulness into positive psychology: A randomised controlled trial of an online positive mindfulness program. Mindfulness, 7(6), 1396-1407. https://doi. org/10.1007/s12671-016-0581-1

Katan, N., Tzafrir, S., \& Guy, E. (2019). Effect of mindfulness practice on self-efficacy among employees in an organization. Academy of Management Proceedings, 2019(1), 13544. https://doi.org/10.5465/ambpp.2019.13544abstract

Keng, S.-L., Smoski, M. J., \& Robins, C. J. (2011). Effects of mindfulness on psychological health: A review of empirical studies. Clinical Psychology Review, 31(6), 1041-1056. https:// doi.org/10.1016/j.cpr.2011.04.006

Leavitt, C. E., Lefkowitz, E. S., \& Waterman, E. A. (2019). The role of sexual mindfulness in sexual wellbeing, relational wellbeing, and self-esteem. Journal of Sex and Marital Therapy, 45(6), 497-509.

Marshall, S. L., Parker, P. D., Ciarrochi, J., Sahdra, B., Jackson, C. J., \& Heaven, P. C. (2015). Self-compassion protects against the negative effects of low self-esteem: A longitudinal study in a large adolescent sample. Personality and Individual Differences, 74, 116-121.

McCormick, M. J. (2001). Self-efficacy and leadership effectiveness: Applying social cognitive theory to leadership. Journal of Leadership Studies, 8(1), 22-33. https://doi.org/10.1177/1071 79190100800102

Medina, A. M., \& Mead, J. S. (2021). An exploration of mindfulness in speech-language pathology. Communication Disorders Quarterly, 42(4), 257-265. https://doi.org/10.1177/15257401 20942141

Nyanaponika. (1972). The power of mindfulness. [San Francisco]: Unity Press.

O'reilly, G. A., Cook, L., Spruijt-Metz, D., \& Black, D. S. (2014). Mindfulness-based interventions for obesity-related eating behaviours: A literature review. Obesity Reviews, 15(6), 453-461. https://doi.org/10.1111/obr.12156

Padhy, M., Monteiro, S. R., \& Chelli, K. (2020). Coping competence, mindfulness, and well-being of Indian adolescents. Psychological Studies, 65(4), 531-535. https://doi.org/10.1007/s12646020-00584-6

Paradise, A., \& Kernis, M. (2002). Self-esteem and psychological well-being: implications of fragile self-esteem. Journal of Social and Clinical Psychology, 21(4), 345-361. https://doi.org/10. $1521 /$ jscp.21.4.345.22598

Park, H. J., \& Dhandra, T. K. (2017). The effect of trait emotional intelligence on the relationship between dispositional mindfulness and self-esteem. Mindfulness, 8(5), 1206-1211.

Pepping, C. A., O'Donovan, A., \& Davis, P. J. (2013). The positive effects of mindfulness on self-esteem. The Journal of Positive Psychology, 8(5), 376-386. https://doi.org/10.1080/17439760. 2013.807353

Pineau, T. R., Glass, C. R., Kaufman, K. A., \& Bernal, D. R. (2014). Self-and team-efficacy beliefs of rowers and their relation to mindfulness and flow. Journal of Clinical Sport Psychology, $8(2), 142-158$.

Powell, A. (2018). Harvard researchers study how mindfulness may change the brain in depressed patients. Harvard Gazette. https://news.harvard.edu/gazette/story/2018/04/harvard-researchersstudy-how-mindfulness-may-change-the-brain-in-depressedpatients/.
Randal, C., Pratt, D., \& Bucci, S. (2015). Mindfulness and selfesteem: a systematic review. Mindfulness, 6(6), 1366-1378. https://doi.org/10.1007/s12671-015-0407-6

Rasmussen, M. K., \& Pidgeon, A. M. (2011). The direct and indirect benefits of dispositional mindfulness on self-esteem and social anxiety. Anxiety, Stress and Coping, 24(2), 227-233. https://doi.org/10.1080/10615806.2010.515681

Rayan, A. (2018). Mindfulness, self-efficacy, and stress among finalyear nursing students. Journal of Psychosocial Nursing and Mental Health Services, 57(4), 49-55.

Roberts, L. R., \& Montgomery, S. B. (2016). Mindfulness-based intervention for perinatal grief in rural India: Improved Mental Health at 12 months follow-up. Issues in Mental Health Nursing, 37(12), 942-951. https://doi.org/10.1080/01612840.2016. 1236864

Rosenberg, M., Schooler, C., Schoenbach, C., \& Rosenberg, F. (1995). Global self-esteem and specific self-esteem: Different concepts, different outcomes. American Sociological Review, 60(1), 141-156.

Rosenberg, M. (1965). Society and the adolescent self-image. Princeton University Press.

Sagula, D., \& Rice, K. G. (2004). The effectiveness of mindfulness training on the grieving process and emotional well-being of chronic pain patients. Journal of Clinical Psychology in Medical Settings, 11(4), 333-342. https://doi.org/10.1023/b:jocs.000004 5353.78755 .51

Sala, M., Rochefort, C., Lui, P. P., \& Baldwin, A. S. (2019). Trait mindfulness and health behaviours: A meta-analysis. Health Psychology Review, 14(3), 345-393. https://doi.org/10.1080/ 17437199.2019.1650290

Samuelson, M., Carmody, J., Kabat-Zinn, J., \& Bratt, M. A. (2007). Mindfulness-based stress reduction in Massachusetts correctional facilities. The Prison Journal, 87(2), 254-268. https://doi.org/10.1177/0032885507303753

Schwarzer, R., \& Jerusalem, M. (1995). Generalized self-efficacy scale. In J. Weinman, S. Wright, \& M. Johnston (Eds.), Measures in health psychology: A user's portfolio. Causal and control beliefs (pp. 35-37). NFER-NELSON.

Sorbero, M. E. (2015). Meditation for depression: A systematic review of mindfulness-based cognitive therapy for major depressive disorder. https://doi.org/10.7249/j.ctt19w7254? refreqid=search-gateway:3fb79d9af09ca73441a7295efc48722a.

Soysa, C. K., \& Wilcomb, C. J. (2013). Mindfulness, self-compassion, self-efficacy, and gender as predictors of depression, anxiety, stress, and well-being. Mindfulness, 6(2), 217-226. https://doi.org/10.1007/s12671-013-0247-1

Splevins, K., Smith, A., \& Simpson, J. (2009). Do improvements in emotional distress correlate with becoming more mindful? A study of older adults. Aging and Mental Health, 13(3), 328-335.

Thompson, B. L., \& Waltz, J. (2007). Everyday mindfulness and mindfulness meditation: Overlapping constructs or not? Personality and Individual Differences, 43(7), 1875-1885.

Verma, J., \& Triandis, H. C. (1999). The measurement of collectivism in India. In W. J. Lonner, D. L. Dinnel, D. K. Forgays, \& S. A. Hayes (Eds.), Merging past, present, and future in crosscultural psychology: Selected papers from the Fourteenth International Congress of the International Association for Cross-Cultural Psychology (pp. 256-265). Swets and Zeitlinger Publishers.

Vidic, Z., \& Cherup, N. (2019). Mindfulness in classroom: Effect of a mindfulness-based relaxation class on college students' stress, resilience. Self-Efficacy and Perfectionism. College Student Journal, 53(1), 130-144.

Vosvick, M., \& Stem, W. (2019). Psychological quality of life in a lesbian, gay, bisexual, transgender sample: Correlates of stress, mindful acceptance, and self-esteem. Psychology of Sexual 
Orientation and Gender Diversity, 6(1), 34-41. https://doi.org/10.1037/sgd0000303

Wei, M., Tsai, P. C., Lannin, D. G., Du, Y., \& Tucker, J. R. (2015). Mindfulness, psychological flexibility, and counseling selfefficacy: Hindering self-focused attention as a mediator. The Counseling Psychologist, 43(1), 39-63.

Yang, C. C., Holden, S. M., \& Carter, M. D. (2017). Emerging adults' social media self-presentation and identity development at college transition: Mindfulness as a moderator. Journal of Applied Developmental Psychology, 52, 212-221.

Yeom, Y.-R., \& Choi, K.-B. (2013). The effect of mindfulness meditation programs on nursing college students' perceived stress, depression, and self-efficacy. Journal of East-West Nursing Research, 19(2), 104-113. https://doi.org/10.14370/ jewnr.2013.19.2.104

Young-Ran, Y., \& Keum-Bong, C. (2013). The effect of mindfulness meditation programs on nursing college students' perceived stress, depression, and self-efficacy. Journal of East-West Nursing Research, 19(2), 104-113.

Publisher's Note Springer Nature remains neutral with regard to jurisdictional claims in published maps and institutional affiliations. 